\title{
Police Body-Worn Cameras: Perceptions of Law Enforcement Leadership
}

\author{
John Ortiz Smykla ${ }^{1} \cdot$ Matthew S. Crow $^{2}$. \\ Vaughn J. Crichlow ${ }^{1}$. Jamie A. Snyder ${ }^{2}$
}

Received: 2 September 2015 / Accepted: 13 November 2015 /

Published online: 4 December 2015

(C) The Author(s) 2015. This article is published with open access at Springerlink.com

\begin{abstract}
Many people are enthusiastic about the potential benefits of police body-worn cameras (BWC). Despite this enthusiasm, however, there has been no research on law enforcement command staff perceptions of BWCs. Given the importance that law enforcement leadership plays in the decision to adopt and implement BWCs, it is necessary to assess their perceptions. This is the first study to measure law enforcement leadership attitudes toward BWCs. The study relies on data collected from surveys administered to command staff representing local, state and federal law enforcement agencies in a large southern county. Among the major perceptual findings are that command staff believe BWCs will impact police officers' decisions to use force in encounters with citizens and police will be more reluctant to use necessary force in encounters with the public. Respondents also believe that use of BWCs is supported by the public because society does not trust police, media will use BWC data to embarrass police, and pressure to implement BWCs comes from the media. Perceptions of the impact of BWCs on safety, privacy, and police effectiveness are also discussed.
\end{abstract}

Keywords Body-worn cameras · Policing · Police leadership perceptions · Technology · Police survey

John Ortiz Smykla

jsmykla@fau.edu

Matthew S. Crow

mcrow@uwf.edu

Vaughn J. Crichlow

vcrichlow@fau.edu

Jamie A. Snyder

jsnyder1@uwf.edu

1 School of Criminology \& Criminal Justice, Florida Atlantic University, 777 Glades Road, Boca Raton, FL 33431, USA

2 Department of Criminology \& Criminal Justice, University of West Florida, 11000 University Parkway, Pensacola, FL 32514, USA 


\section{Introduction}

Several high-profile incidents involving police use of deadly force in recent months have resulted in increased scrutiny of officer behavior and police-community relations by the media, policy-makers, civil rights groups, and academics. The controversy and conflicting accounts surrounding the deadly police shootings of Michael Brown, Tamir Rice, and other lethal force incidents have led to nationwide interest in the issue of police body-worn cameras (BWCs). Politicians, victims' families, civil rights groups, and some police administrators have called for equipping police officers with body-worm cameras in an effort to increase transparency and accountability (Bradner, 2015; Fieldstadt, 2014; King and Disis, 2015; Morgan, 2015). In December 2014, President Obama created a Task Force on 21st Century Policing and proposed an investment of $\$ 75$ million to purchase 50,000 BWCs for police throughout the United States (Office of the White House Press Secretary, 2015).

Proponents of BWCs assert that they will increase police accountability and transparency, improve police officer conduct and citizen behavior, reduce unwarranted complaints against police officers, increase officer and citizen safety, decrease police use of force incidents, assist in criminal prosecutions, facilitate officer training, and build trust between the police and their communities (Macari, 2015; NIJ, 2012; Miller, Toliver, and Forum, 2014). Although the relatively few studies investigating BWCs provide mixed support for these claims, several risks and concerns associated with BWCs also exist. A recent article in the Harvard Law Review (HLR) cautioned against expedient adoption of BWCs based on the argument that once deployed, BWC programs will be difficult to scale back (Considering police body cameras: Developments in the law, 2015). The HLR article argued that the implementation of BWC programs without concomitant legal reform may have unintended consequences. Concerns about privacy for both police officers and citizens are paramount among those who advocate caution in the push to implement BWC programs (Abdollah, 2014; Stanley, 2015). Open-records laws in many jurisdictions compound this issue. Police officers often encounter witnesses, victims, and suspects in their most vulnerable moments, including during mental health crises, domestic disputes, and following violent and/or sexual victimizations. Questions persist regarding who will have access to the video footage captured by BWCs and the policies and guidelines related to public release of videos. As of May 18, 2015, ten states (Arizona, Colorado, Florida, Maryland, New Hampshire, North Dakota, Oklahoma, Pennsylvania, Utah, and Vermont,) enacted laws related to BWCs, several of which directly address public disclosure and privacy issues (National Conference of State Legislature (NCSL), 2015).

Implementation of BWCs also involves considerable investments in resources related to the cost of purchasing equipment and storing data, officer training, and the time required to download and review recorded video. Although grant programs have been developed to implement BWC programs, ongoing equipment maintenance and data storage will be costly for departments. Police administrators and local governments will likely be faced with difficult financial decisions when considering BWCs, including how funding for officer salaries and other equipment maintenance is impacted. A recent news article, for example, estimated the cost of implementing body-worn cameras for all patrol officers in Milwaukee, WI as the same cost of adding 12 new police officers (Stephenson and Luthern, 2015). 
In 2013, the Police Executive Research Forum (PERF) conducted a survey of 500 law enforcement agencies throughout the United States; of the 254 departments that responded to the survey, only $25 \%$ reported that they used BWCs at the time (Miller et al., 2014). Undoubtedly, the number of agencies using BWCs has increased since that time, but reliable statistics on the extent of implementation are not currently available. The push from the media, politicians, policy-makers, the public, and assembled task forces for agencies to adopt the use of BWCs has not, however, been based on a large body of research on the costs and benefits of the technology or the perceptions of stakeholders regarding its use.

Rosenbaum (2015), for example, recently argued for "rigorous research on BWCs now so that science can help guide policy and practice" (p. 7). Similarly, Jennings and Fridell (2015) pointed to the lack of research attention on the perceptions of those who have a stake in the implementation process, arguing that:

...it is important to assess the buy-in from these key stakeholders, including midand upper-level police management, toward BWCs...Ultimately, the consequences of proceeding without first answering germane research questions such as these may lead to an ineffective use of scarce resources and an improperly informed rationale for small- or wide-scale adoption of BWCs (p. 7).

Despite the caution advocated for by scholars, police departments throughout the United States continue to adopt BWCs. Many of the advocates for BWCs, however, cite a single study from Rialto, CA (Ariel, Farrar, \& Sutherland, 2015) that found several benefits of using the technology for that one police department. The current study aims to contribute to this underdeveloped area of research by reporting on the perceptions of police law enforcement leadership from multiple agencies regarding BWCs. Command staff perceptions BWCs are important for several reasons, including their impact on decisions to adopt BWCs in their departments, discretion regarding the distribution of funding and resources for BWC programs, input on policy development, and potential influence on officer perceptions and practice. The state of the extant research literature on BWCs is reviewed, followed by the description of the current study and its findings.

\section{Literature Review}

As previously discussed, although there are numerous claims to the perceived benefits and drawbacks to BWCs, there is scant scientific literature to support or refute most of these claims. To date, there has only been one randomized controlled trial evaluation of BWCs that has been peer reviewed and published (Ariel, et al., 2015). England's College of Policing published the results of a randomized controlled trial on the impact of BWCs on the outcomes of domestic abuse incidents, but those results were not peer reviewed and significant problems were reported related to the fidelity of the trial (Owens, Mann, and McKenna, 2014). Most of the remaining literature is either correlational or agency generated and suffers from methodological weaknesses that limit drawing policy inferences. 
We draw on the Maryland Scientific Methods Scale (SMS) developed by Sherman, Gottfredson, MacKenzie, Eck, Reuter, and Bushway (1998) to rate the internal validity of the impact and perception studies discussed below (see Table 1). The SMS scale rates studies from level 1 (correlation studies) to level 5 (randomized controlled trials).

\section{Impact Studies}

We located seven studies that purport to demonstrate the impact of BWCs on crime and other outcomes, and one study that measured officers' perception of BWCs. According to the SMS, there are two level 5 studies (Ariel, Farrar, and Sutherland, 2015; Owens et al., 2014), although the Ariel et al. (2015) study was the only peer-reviewed randomized control trial. Two published studies report correlations between BWCs and outcomes or officer perceptions (Victoria Police Department, 2010; Jennings, Fridell, and Lynch, 2014, respectively); three published studies measure outcomes before and after implementation of BWCs without control conditions (Police and Crime Standards Directorate, 2007; ODS Consulting, 2011; Katz, Choate, Ready, and Nuño, 2014); and one published report includes a comparison of the effects of BWCs between groups without using random assignment (Miller et al., 2014). We now turn to a discussion of each in temporal order to demonstrate the growth in literature across time and place.

British police were the first to show an interest in BWCs (also known as head cameras or body-worn video in the U.K.). BWCs were first used on a limited basis for eight weeks in 2006 in Plymouth, England during a domestic violence enforcement campaign (Police and Crime Standards Directorate, 2007). The Plymouth Basic Command Unit commenced a 17-month study of BWCs in which 300 officers participated. The U.K. Home Office commissioned Devon and Cornwall Police to analyze the results and Process Evolution (a U.K. company specializing in evidence-based consulting) to produce recommendations for change.

The results of the Plymouth pre/post analysis of data from 2005/2006 were compared against data from 2006/2007. Implementation of BWCs resulted in a $1.2 \%$ reduction in violent crime, a $12.8 \%$ reduction in wounding, ${ }^{1}$ an increase of $26.9 \%$ in sanction detections $^{2}$ for violent crime, an increase of $7.3 \%$ in the number of violent crimes prosecuted, a reduction of $22.4 \%$ on officer time spent on paperwork, and an overall reduction in citizen complaints against the police by $14.3 \%$. The design may have established causal order, but failed to rule out many threats to internal validity.

In July 2009, the Victoria (British Columbia, Canada) Police Department became the first police agency in North America to implement BWCs and in-vehicle video (IVV) (Victoria Police Department, 2010). The trial period lasted only four months and included 20 police officers, but it is unclear how many officers were assigned BWCs and IVVs. The department used four BWCs, available for voluntary use primarily by foot and bicycle patrol officers. IVVs were installed in three police cars and on one police motorcycle. Unlike Plymouth, the Victoria PD research found that BWC officers

\footnotetext{
${ }^{1}$ Wounding in the U.K. refers to assault that breaks the outer skin of the victim by an offender (Offenses Against the Person Act 1861, Section 18, Crown Prosecution Service).

2 A sanction detection is one that leads to charge, summons, caution, formal warning, youth reprimand, or the offense being taken into consideration ("Sanctioned Detections Explained," Inspector Lin Houldershaw, Youth Justice Board, November 2011).
} 
Table 1 Rating body-worn camera impact and perception research studies using the Maryland scientific methods scale

Level 1: Studies demonstrating a correlation between a program and a measure of crime at one point in time. The lack of any controls makes it impossible to conclude that any change in the outcome is due to the independent variable, as opposed to a multitude of other possible factors.

1. Victoria Police Department (2010)

- No conclusions on police outcomes

- In spite of small sample size, officers expressed support

2. Jennings et al. (2014)

- Officer perceptions favorable to BWC adoption

- Officer perceptions mixed regarding impact of BWC on behavior

Level 2: Measures of crime before and after the program, with no control condition. This design establishes causal order but fails to rule out many threats to internal validity. Thus, other factors coinciding with the program may have produced the observed decline in crime.

1. Police and Crime Standards Directorate (2007)

- Reductions in violent crime, wounding, time spent on paperwork and citizen complaints

- Increase in sanction detection and violent crimes prosecuted

2. ODS Consulting (2011)

- Decline in breach of peace, vandalism, and minor and serious assaults (Aberdeen)

- Reduction in violent crime and malicious mischief (Renfrewshire)

- Citizens in both areas believed cameras make the community safer, supported their use, reduced crime, and all police should wear

3. Katz et al. (2014)

- Domestic violence calls most likely to be recorded

- BWC officers made more daily arrests and received fewer citizen complaints

- BWC cases more likely to be initiated, result in charges filed and guilt

- BWC officers believed cameras make officers behave professionally, provide more accurate account of incidents, improve quality of evidence and should be expanded

Level 3: A comparison between two or more comparable units of analysis. One problem with the design centers on selection effects due to the non-equivalence of the experimental and control conditions. Thus, there is no assurance that the groups being compared were similar prior to the implementation of the program.

1 Miller et al. (2014)

- Fewer citizen complaints

- Fewer use of force incidents

Level 4: Measures of crime before and after the program matching a program group with one or more control groups. Matching units of analysis maximizes the equivalence of experimental and control groups.

However matching raises the potential for selection bias.

None reported

Level 5: Random assignment of program and control conditions to units. Random assignment is the "gold standard" in evaluation because it best eliminates selection bias when the sample size is sufficient. Randomized control studies have the highest internal validity.

1 Ariel, Farrar, \& Sutherland (2015). Peer reviewed

- Fewer incidents of use of force

- Reduction in citizen complaints

2 Owens et al. (2014). Not peer reviewed

- Low usage of cameras affected outcome measures

- Higher proportion of domestic abuse incidents resulted in criminal charge 
reported spending more time completing paperwork when video evidence was included. This research did not report data on issues of police accountability or effectiveness of BWC police in their response to crime. The 75-page report covered technical issues related to BWCs and IVVs such as development and implementation of policy, accountability, data collection, storage and use, training, and equipment selection, but no conclusions about the effectiveness of BWCs can be drawn from the report.

In 2011, Organizational Development and Support (ODS) Consulting studied the pilot BWC programs in Renfrewshire and Aberdeen, Scotland. In Renfrewshire three BWCs were deployed in 2006-2007 (no results provided). Three years later the number was increased to 38 BWCs. The first eight months of operation were reviewed (June 2009 - January 2010). In Aberdeen, a pilot program using 18 BWCs (later increased to 39) was introduced in June 2010 in two areas and studied over a three-month period beginning June 1, 2010.

In the Aberdeen areas where BWCs were deployed, the authors compared outcomes from 2009 to 2010 and found declines in breach of peace offenses (19\%), vandalism (29\%), minor assaults $(27 \%)$, and serious assaults (60\%), for an overall decline in crime of $26 \%$ compared to a $1 \%$ reduction in overall crime for all areas in Aberdeen (ODS Consulting, 2011, p. 7). The authors also reported an impact of BWCs on guilty plea rates and citizen complaints.

Unlike the pilot program in Aberdeen, BWCs in Renfrewshire were deployed across the entire city. ODS researchers compared Renfrewshire with crime information from Renfrewshire and Inverclyde police divisions on the first eight months of BWC operation (June 2009 - January 2010). ${ }^{3}$ Inverclyde did not deploy BWCs. Although the report indicates greater reductions in violent crime and malicious mischief and an impact on guilty pleas associated with BWCs, the study design limits the validity of the findings.

In 2014, England's College of Policing published the results of a study designed as a randomized controlled trial to examine the impact of BWCs on the outcomes of domestic abuse incidents in Essex, England (Owens et al., 2014). However, as we mentioned earlier, the findings were not independently peer reviewed and significant implementation issues were reported. All 308 Essex police officers at the rank of constable were randomly assigned to either treatment or control groups. In total, 80 officers were randomly assigned to wear BWCs, but only 70 eventually wore them, and 238 were randomly assigned to a control group. Police responded to 7609 domestic abuse incidents during the study period. Of these incidents, $36 \%$ were responded to by police wearing BWCs. However, even though the experiment was designed to evaluate the impact of BWCs on the outcomes of domestic abuse incidents, low usage of the cameras by officers may have had an effect on outcome measures.

Online surveys given to officers at the end of the four month period found that only one in six officers used the camera in all domestic abuse incidents, as required by policy, because either their equipment was broken or they chose not to wear or use them (Owens et al., 2014). The disparity may even be higher because only 44 of the 70 BWC officers completed the online survey. Researchers contextualize the findings with a selection of questions from the officer survey and 15 officer interviews. Results

\footnotetext{
${ }^{3}$ Researchers did not explain why they combined Renfrewshire and Inverclyde police divisions as the comparison group.
} 
showed that a higher proportion of domestic abuse incidents attended by BWC officers resulted in a criminal charge compared to control group officers (81\% and $72 \%$, respectively).

In October 2012, the Mesa police department (MPD) implemented a one-year trial of BWCs (Rankin, 2013; Miller et al., 2014). Fifty patrol officers wore BWCs and 50 did not. Across the one-year trial period, researchers at Arizona State University (ASU) reported $60 \%$ fewer citizen complaints against officers wearing BWCs compared to control-group officers, $40 \%$ fewer total complaints overall, and $75 \%$ total fewer use of force incidents overall during the trial period than they did the year prior when they were not using BWCs (Rankin, 2013; Miller et al., 2014). Officers without BWCs had nearly three times more complaints eight months after BWCs were adopted compared to officers who had BWCs.

In April 2013, the Phoenix police department implemented a BWC project in its Maryvale precinct intended for two purposes: 1) to increase police accountability; and 2) to increase the effectiveness of the police in their response to domestic violence (Katz et al., 2014). The Maryvale precinct is divided into two areas and all 50 to 55 officers in one area were issued BWCs. Analysis of data relied on a before-after comparison.

Katz et al. (2014) report that across the study period, only $13.2 \%$ to $42.2 \%$ of incidents were recorded, with domestic violence calls most likely to be recorded. Arrest data show that during both the pre- and post-deployment periods, control officers made more total arrests compared to officers wearing BWCs. However, when researchers looked at average daily arrests, they found that BWC officers increased their daily arrests by $42.6 \%$, which was nearly triple, the control group (14.9\%). When researchers looked at trend data in resisting arrests between the two groups, they found that both groups experienced a substantial increase in overall resisting arrest incidents. According to Katz et al. (2014), "These increases are in part driven by increases in arrest for passive resistance" (p. 31).

Katz et al. (2014) also reported that citizen complaints against officers who wore the cameras declined by $23 \%$, compared to a $10.6 \%$ increase among comparison officers and a $45.1 \%$ increase among patrol officers in other precincts. Furthermore, officers who wore cameras and received a complaint were less likely to have the complaint upheld when compared to the comparison group and patrol officers in other precincts.

Finally, Katz et al. (2014) compared pre- and post-deployment data on the impact of BWCs across the entire jurisdiction on domestic violence case processing. They found that following BWC deployment, cases were more likely to be initiated, result in charges filed, and result in guilty plea or guilty verdict.

Although the above studies seem to suggest a positive impact of BWCs, it is important to recognize that the research designs were weak and many of the analyses were not produced by independent evaluators. The only known peer-reviewed study utilizing a randomized controlled trial examined the use of BWCs in Rialto, CA (Ariel et al., 2015). In the Rialto study, all police shifts $(n=988)$ were randomly assigned to either experimental or control conditions over 12 months beginning February 2012. Officers in experimental shifts wore BWCs. Officers in control shifts did not. After 12 months, the researchers found that control group shifts had twice as many incidents of use of force as shifts with BWCs (17 and 8, respectively). In terms of citizen complaints against officers, the researchers were unable to compute a treatment effect 
due to the low occurrence of complaints in both treatment and control groups. Only three incidents of citizen complaints were filed during the experiment, two against officers wearing BWCs and one against an officer not wearing a camera. Although, when the researchers employed a pre/post analysis they found a significant overall reduction of citizens' complaints from $24^{4}$ filed 12 months before the experiment started to three during the trial period.

However, because of behavior dynamics that might have led to the decline in the use of force (changes in officer and citizen behavior, changes in civilian reporting patterns, or an increased culture of accountability in the department) and the fact that the control group worked dependently with the experimental group and was aware of the treatment condition, Ariel et al. (2015) discuss the potential interference of the Hawthorne and John Henry effects and call on researchers, police agencies, and governments to invest further time and effort in replicating their findings before policy changes are considered.

\section{Perception Studies}

Jennings et al. (2014) conducted preliminary research on police officers' perceptions of BWCs. Ninety-one officers completed a survey before BWCs were placed in the field in Orlando, Florida. The survey tapped officers' general perceptions of BWCs, officers' perceptions of the perceived effects of BWCs on citizen behavior and their own behavior, and on the behavior of other officers. The researchers reported that the Orlando police officers were generally supportive of the use of BWCs in their agency. Over $60 \%$ agreed that the agency should adopt BWCs and $77 \%$ agreed that they would feel comfortable wearing them. Few of the officers $(18.7 \%)$, however, believed that BWCs would make them feel safer.

Jennings et al. (2014) also reported that officers in the Orlando study were mixed in their perceptions of how BWCs would impact officer behavior. For example, officers were more likely to agree that BWCs would change the behavior of other officers than they were to believe BWCs would impact their own behavior. The authors also reported a few differences in perceptions of BWCs across officer sex and race. Specifically, male officers were more likely than female officers to believe BWCs would influence their own behavior, while female officers were more likely to agree that BWCs would reduce complaints against officers. The only reported difference between the perceptions of White and Non-White officers involved use of force. Non-White officers were comparatively more likely to agree that BWCs would reduce their own use of force.

Several of the aforementioned impact studies also included analysis of officer and/or citizen perceptions of BWCs. For example, the Victoria Police Department study included an online survey of six BWC officers and nine IVV officers at the conclusion of the BWC trial period. In spite of the small sample, respondents expressed support for the expanded use of BWC and IVV, and agreed that they made their job easier and the equipment was easy to use (Victoria Police Department, 2010, p. 42).

\footnotetext{
${ }^{4}$ Other sources list this as 28 citizen complaints - Ariel, B., \& Farrar, T. (March 2013). Self-awareness to being watched and socially-desirable behavior: A field experiment on the effect of body-worn cameras on police use-of-force. Washington, DC: Police Foundation.
} 
As part of the Mesa BWC study, Katz et al. (2014) examined the impact of BWCs on patrol officers' attitudes and behavior at multiple points in time. Results from the first survey found that almost 8 out of 10 officers believed that BWCs would cause patrol officers to behave more professionally (as cited in White, 2014). However, only $23 \%$ believed the department should adopt BWCs in the future, and less than half believed other officers would welcome the presence of a BWC at an incident.

In Phoenix, Katz et al. (2014) also examined officer perceptions of BWC. ${ }^{5}$ Their findings suggest that the majority of BWC officers agreed that BWCs provide a more accurate account of an incident and improve the quality of evidence. BWC officers were also more likely to agree that BWCs should be 1) expanded to other departments, 2) adopted throughout the city, and 3) that the advantages of BWCs outweigh the disadvantages.

Conversely, comparison of officer perceptions in Phoenix prior to BWC deployment with perceptions post-deployment indicated a less positive perceived impact on prosecution of offenses (Katz et al., 2014). Specifically, prior to deployment, officers were more likely to agree that BWCs would make it 1) easier to work with the prosecutor's office when submitting evidence, 2) easier to prosecute domestic violence offenders, and 3 ) easier to help prosecute domestic violence cases when the victim is unwilling to testify, than after the cameras were implemented.

Only two known surveys to date have examined public perceptions of BWCs. ODS Consulting (2011) surveyed 701 citizens in Northfield and Mastrick and reported that the majority of respondents believed that BWCs would make their community safer and supported the use of BWCs by police. The same researchers conducted an online survey of 97 citizens in Renfrewshire and found once again that the majority of respondents believed BWCs would help reduce crime and antisocial behavior and believed that all police should wear BWCs (ODS Consulting, 2011).

As discussed previously, only one peer-reviewed randomized controlled trial tested the impact of BWCs on police use of force and citizen complaints (Ariel et al., 2015). The remaining studies investigating BWC impact are instructive, but their methodologies are weak as measured by the SMS and most have not been peer-reviewed. The current study furthers the methodology of attitude survey research by Jennings et al. (2014) and the discussion of the role of leaders in implementation research by Young (2014) and Drover and Ariel (2015), by surveying the attitudes of law enforcement leadership in one southern county, many of whom, as we shall show, are not currently using BWCs. Their attitudes on the perceptual domains discussed here and elsewhere are critical indicators of their support and future direction of BWCs.

\section{Methods}

This study examined law enforcement command staff perceptions of BWCs in Sunshine County. Sunshine County is a large southern county with 27 local law enforcement agencies, home to a number of state and federal law enforcement agencies, and a population of approximately 1.3 million people. Once a month the command staff

\footnotetext{
${ }^{5}$ Researchers limited discussion of officer perceptions to BWC officers only because of contamination results showed that comparison officers' perceptions mirrored those of the target group after a short period.
} 
of the law enforcement community meet to discuss issues of mutual concern. The researchers contacted the chair of the command staff organization and asked if we could administer an anonymous survey on the command staff's perceptions of BWCs. Our request was approved and we administered the survey at their monthly meeting in March 2015. Representatives from 36 agencies signed in. Response rate was $67 \%$.

Twenty-nine items were used to measure command staff perceptions of BWCs. Survey items were developed based on prior literature and focus group meetings with police officers. The questions were divided into 8 perceptual domains - Officer Behavior, Officer Effectiveness, Evidentiary Impact, Privacy, Safety, Use of Force, Impact on Citizens, and Public/Media Impact.

A "framing" question was also asked to gauge overall perceptions on the use of BWCs - "I support the use of BWCs in my department." Law enforcement command staff responded to each item using a 5 point Likert scale, with " 1 " indicating "strongly agree" and "5" indicating "strongly disagree." In addition, respondents were asked whether the agency was currently using BWCs, planning to use them in the future, or considering their use. Twenty-four surveys were completed and returned.

Descriptive statistics were used to examine demographic characteristics of the command staff. Table 2 shows that the majority of respondents identified as either "Director/Chief/Sheriff" (39\%) or "Deputy/Assistant Chief/Sheriff” (26\%). The remaining respondents identified as "Major or Colonel" (22\%) or "Captain/Other" (13\%). Seventy-four percent of the respondents indicated they were male and $80 \%$

Table 2 Descriptive statistics on demographic characteristics of law enforcement command staff $(n=24)$

\begin{tabular}{|c|c|c|c|c|c|}
\hline & $\%$ & Mean & Lowest & Highest & SD \\
\hline Age & & 51.6 & 39 & 65 & 6.71 \\
\hline Less than 50 years & $39 \%$ & & & & \\
\hline 50 years and over & $61 \%$ & & & & \\
\hline Sex & & - & - & - & - \\
\hline Male & $74 \%$ & & & & \\
\hline Female & $26 \%$ & & & & \\
\hline Race & & - & - & - & - \\
\hline White & $80 \%$ & & & & \\
\hline Non-White & $20 \%$ & & & & \\
\hline Education & & - & - & - & - \\
\hline Bachelors or some college & $43 \%$ & & & & \\
\hline Masters or higher & $57 \%$ & & & & \\
\hline Years of experience in law enforcement & & 26.8 & 18 & 41 & 9.25 \\
\hline Less than 20 years & $19 \%$ & & & & \\
\hline 20 years or more & $81 \%$ & & & & \\
\hline Rank & & - & - & - & - \\
\hline Director/Chief/Sheriff & $39 \%$ & & & & \\
\hline Deputy Chief/Assistant Chief & $26 \%$ & & & & \\
\hline Major/Colonel & $22 \%$ & & & & \\
\hline Captain/Other & $13 \%$ & & & & \\
\hline
\end{tabular}


identified as White. On average, the officers were approximately 52 years of age $(\mathrm{SD}=6.71)$, with the youngest command staff member being 39 and the oldest command staff member being 65 years of age. The command staff had an average of 27 years $(\mathrm{SD}=9.25)$ experience in law enforcement. The majority of respondents reported having earned a master's degree or higher $(57 \%)$.

\section{Findings}

The findings showed that half of the command staff members surveyed indicate that they are supportive of the use of BWCs. This was in response to the statement, "I support the use of body-worn cameras in my department" (See Fig. 1). One-third of the respondents disagree or strongly disagree with this statement. The survey also asked respondents whether their departments had already adopted BWCs, had plans to adopt BWCs, were considering adopting BWCs, or were not considering adopting BWCs. Of the 24 respondents, three indicate that their departments were currently using body-worn cameras, one department has made plans to use BWCs in the future, and 9 departments $(38 \%)$ are considering using BWCs in the future. Six respondents indicate that their departments are not considering BWCs in the future $(25 \%)$ and five selected 'Other' (This could reflect that respondents had no thoughts about the use of BWCs in their departments, or that they were undecided).

The authors also examined the level of support for the use of body-worn cameras across categories that indicate respondents' current situation regarding the use of BWCs. The three who were currently using BWCs indicated strong support for the use of BWCs. The respondent who planned on using them in the future was also supportive. However, the nine respondents who were considering using in the future had responses ranging from agreement to strong disagreement. The responses of command staff members who were not considering using BWCs in the future (along with those who selected 'Other'), were also mixed.

Figures 1, 2, 3, 4, 5, 6, 7, and 8 graphically illustrate command staff perceptions of BWCs on each of the eight domains. Leadership perceptions for BWCs and the impact

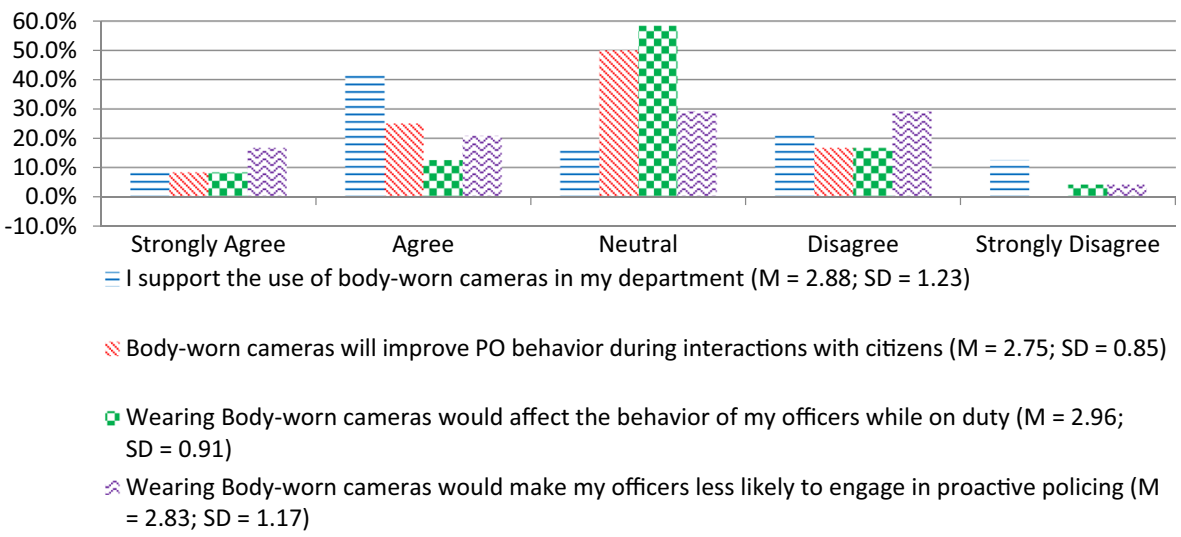

Fig. 1 Support for body-worn cameras and officer behavior domain 


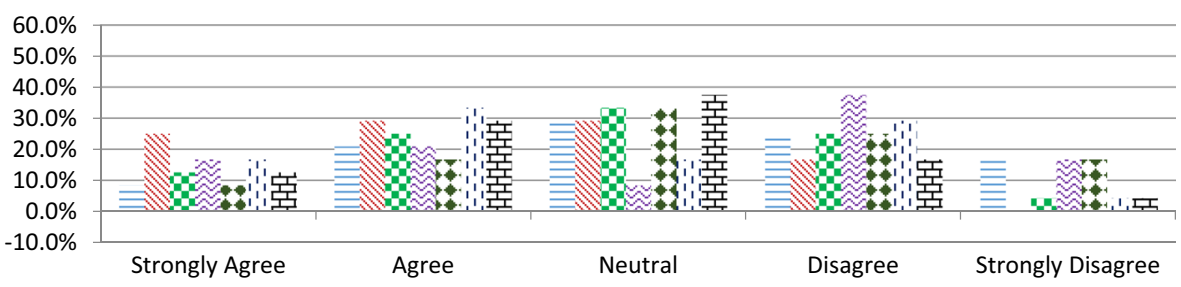

$=$ Body-worn cameras will help police officers do their job $(M=3.21 ; S D=1.22)$

Body-worn cameras will reduce unwarranted complaints against police officers $(M=2.38 ; S D=$ 1.06)

5 Body-worn cameras will be a distraction for officers and will impede on their ability to properly react to emergency situations $(M=2.83 ; S D=1.09$ )

$\approx$ The implementation of body-worn cameras will make it more difficult to recruit and retain quality police officers $(M=3.17 ; S D=1.40)$

:- Overall, wearing a body-worn camera would make it easier for officers in my department to do their jobs ( $M=3.25$; SD = 1.19)

I! The maintenance and upkeep of the body-worn camera would take time away from normal duties performed by my officers ( $M=2.71 ; S D=1.20$ )

$\neq$ Wearing a body-worn camera would cause my officers to experience extra stress ( $M=2.71 ; \mathrm{SD}=$ 1.04)

Fig. 2 Officer effectiveness domain

on officer behavior are shown in Fig. 1. Several notable findings emerged. The majority of respondents $(50 \%)$ support the use of BWCs in their agencies while only one-third disagree or strongly disagree $(\mathrm{M}=2.88 ; \mathrm{SD}=1.23)$. A majority $(50 \%)$ express a neutral position when asked if BWCs would improve police officer behavior during interactions with citizens, but one third agree or strongly agree $(\mathrm{M}=2.75 ; \mathrm{SD}=0.85)$. Almost six in ten $(58.3 \%)$ are neutral when asked if wearing a BWC would affect officer behavior while on duty, but two in ten (20.9\%) agree or strongly agree $(\mathrm{M}=2.96 ; \mathrm{SD}=0.91)$. When asked if BWCs would make officers less likely to engage in proactive policing, no clear pattern emerged $(\mathrm{M}=2.83 ; \mathrm{SD}=1.17)$.

Figure 2 displays command staff perceptions of the impact of BWCs on officer effectiveness. With two exceptions, there is not strong support for BWCs in terms of officer effectiveness. First, command staff is split on a number of questions related to officer effectiveness. Approximately as many respondents agree/strongly agree as disagree/strongly disagree that BWCs will help police officers do their job and that BWCs will be a distraction for officers and impede on their ability to properly react to

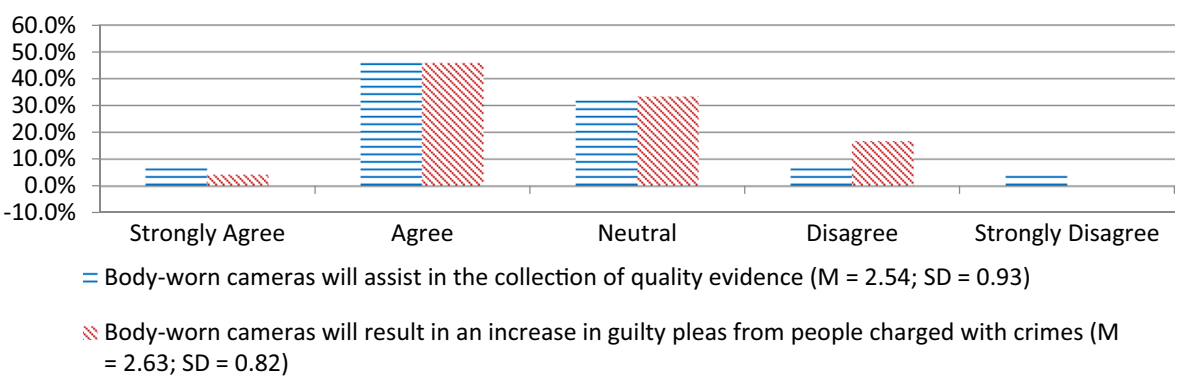

Fig. 3 Evidentiary impact domain 


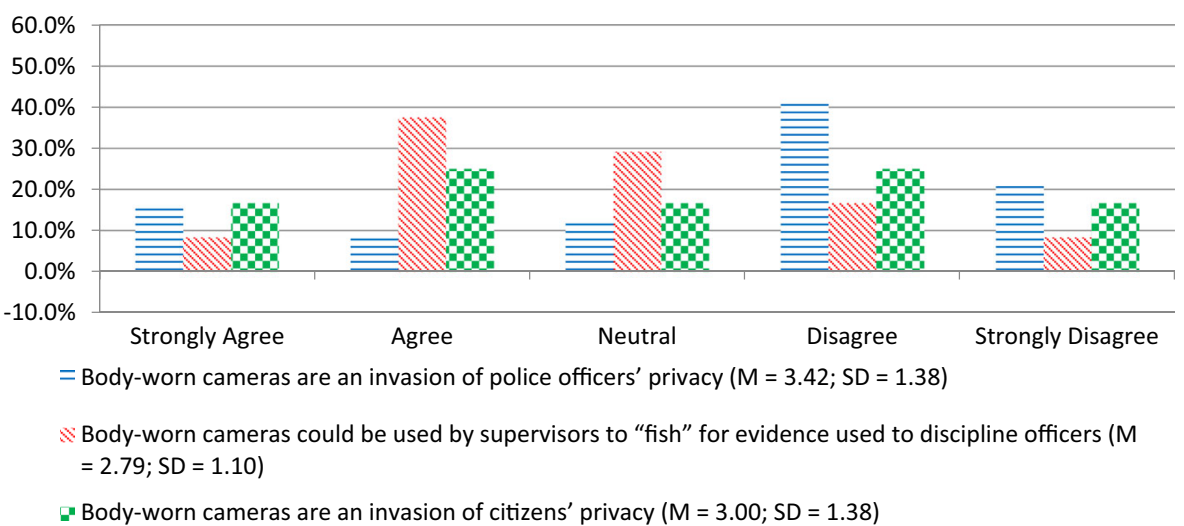

Fig. 4 Privacy domain

emergency situations $(\mathrm{M}=3.21 ; \mathrm{SD}=1.22$ and $\mathrm{M}=2.83 ; \mathrm{DS}=1.09$, respectively). The majority $(50 \%)$ of respondents also believe that the maintenance and upkeep of BWCs will take time away from normal duties $(\mathrm{M}=2.71$; $\mathrm{SD}=1.20)$.

In addition, $40 \%$ believe that BWCs will cause officers to experience extra stress $(\mathrm{M}=2.71 ; \mathrm{SD}=1 / 04)$, and $40 \%$ do not believe that BWCs will make it easier for officers to do their jobs $(\mathrm{M}=3.25$; $\mathrm{SD}=1.19)$. Support for the impact of BWCs on police effectiveness is found in two areas. The majority (54\%) of respondents believe that BWCs will reduce unwarranted complaints against police officers $(\mathrm{M}=2.38$; $\mathrm{SD}=1.06$ ), and the same percentage believe that the implementation of BWCs will not make it difficult to recruit and retain quality police officers $(\mathrm{M}=3.17, \mathrm{DS}=1.40)$.

The majority of command staff believe that BWCs will have a positive impact on evidentiary issues (Fig. 3). Over one-half (54.1\%) agree/strongly agree that BWCs will assist in the collection of quality evidence $(\mathrm{M}=2.54 ; \mathrm{SD}=0.93)$ and $50 \%$ agree/strongly agree that BWCs will result in an increase in guilty pleas from people charged with crimes $(\mathrm{M}=2.63 ; \mathrm{SD}=0.82)$. One-third of respondents expressed a neutral belief for each question.

On the issue of privacy (Fig. 4), two out of three respondents (62.5\%) do not believe that BWCs are an invasion of a police officer's privacy $(\mathrm{M}=3.42 ; \mathrm{SD}=1.38)$, but they are evenly split (41.7\% agree/strongly agree vs. $41.7 \%$ disagree/strongly disagree) on

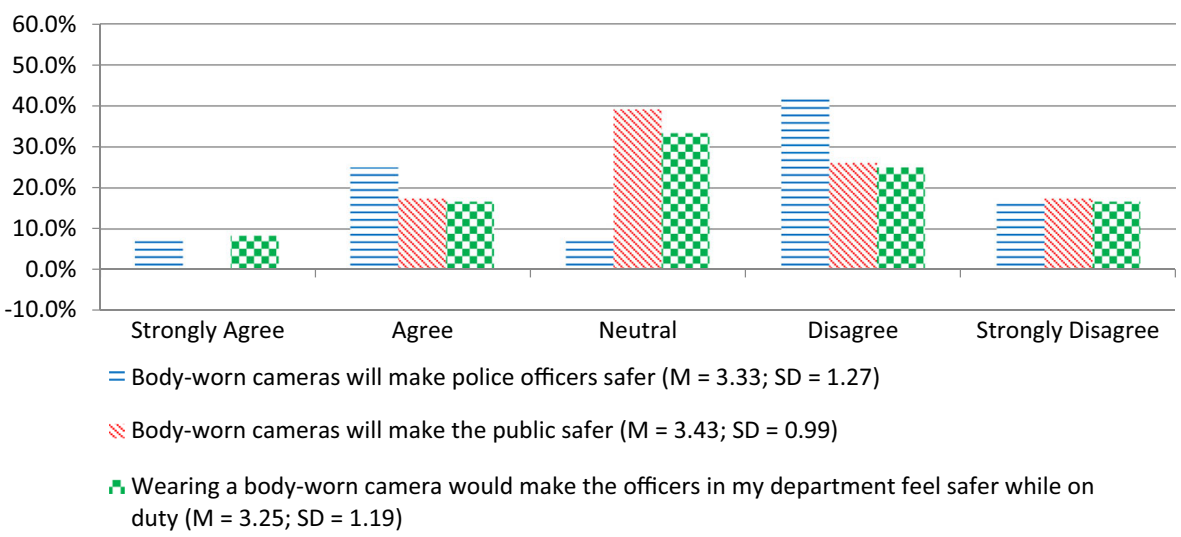

Fig. 5 Safety domain 


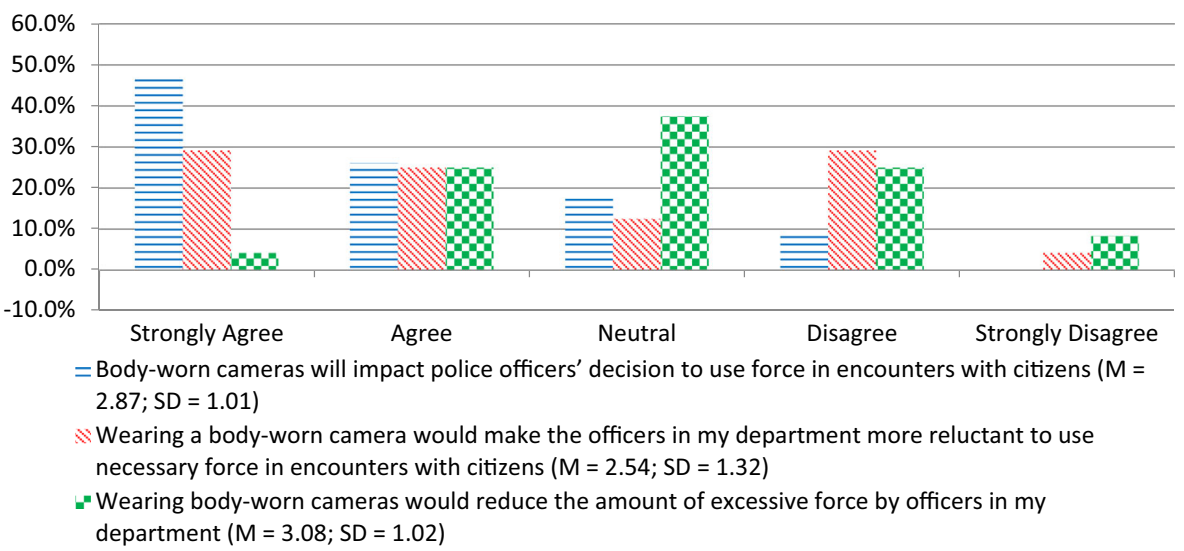

Fig. 6 Use of force domain

whether BWCs are an invasion of citizens' privacy ( $\mathrm{M}=3.00$; $\mathrm{SD}=1.38)$. Furthermore, almost one-half (45.8 \%) agree/strongly agree that BWCs could be used by supervisors to "fish" for evidence used to discipline officers. Others adopted either a neutral position (29.2\%) or express disagreement $(25 \%)(\mathrm{M}=2.79 ; \mathrm{SD}=1.10)$.

When queried on the questions of officer and citizen safety (Fig. 5), only $33.3 \%$ of command staff agree/strongly agree that BWCs will make officers safer, whereas $58.4 \%$ disagree $(\mathrm{M}=3.33 ; \mathrm{SD}=1.27)$. Only $17.4 \%$ of respondents agree that $\mathrm{BWCs}$ will make the public safer compared to $43.5 \%$ who disagree/strongly disagree $(\mathrm{M}=3.43$; $\mathrm{SD}=0.99)$. One-third of respondents express a neutral position on whether wearing a BWC would make the officers in their agencies feel safer while on duty compared to $25 \%$ who agree/strongly agree and $41.7 \%$ who disagree/strongly disagree.

Command staff were also asked their perceptions about the impact of BWCs on officers' use of force, which is where we found the most consistency among the command staff (Fig. 6). Nearly half (47.8\%) of respondents agree that BWCs will impact police officers' decision to use force in encounters with citizens $(\mathrm{M}=2.87$; $\mathrm{SD}=1.01)$. When asked what impact BWCs might have in encounters with citizens, over half $(54.2 \%)$ believe BWCs will make officers more reluctant to use necessary

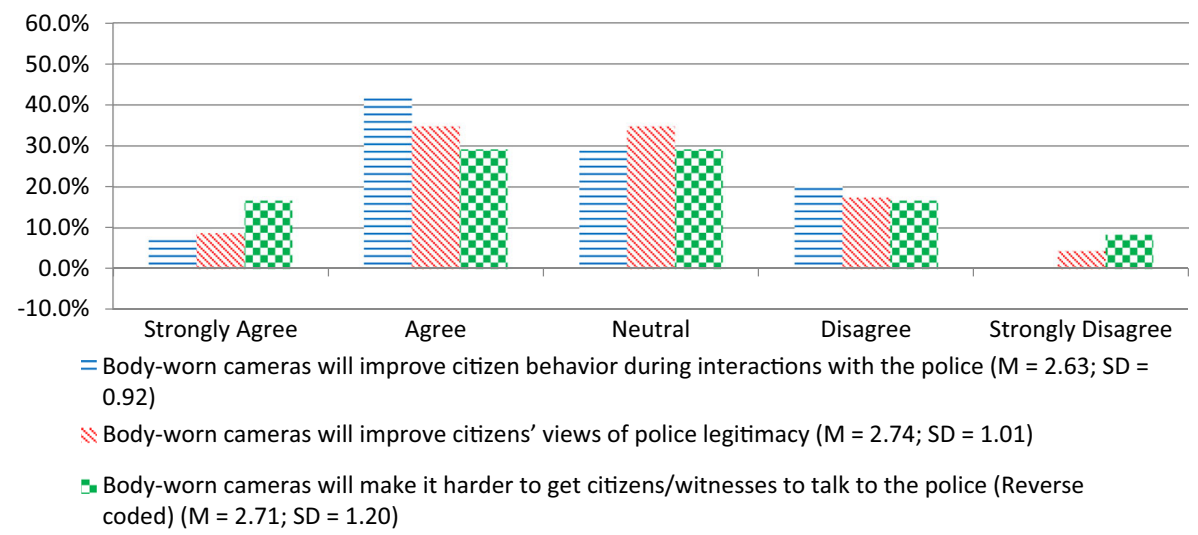

Fig. 7 Impact on citizens domain 


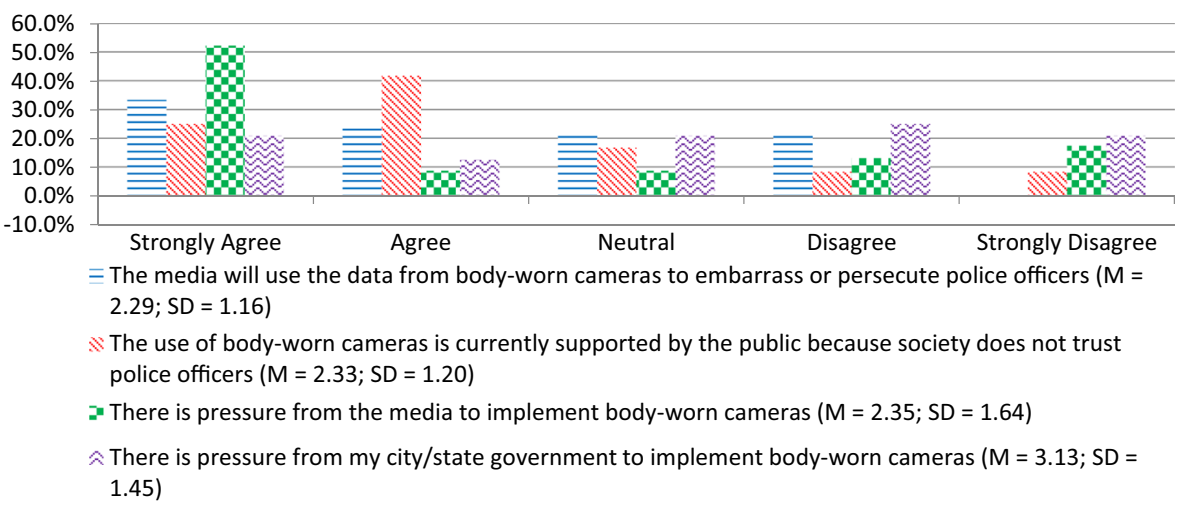

Fig. 8 Public/media domain

force in encounters with citizens $(\mathrm{M}=2.54$; $\mathrm{SD}=1.32)$. Command staff appear to be split on whether BWCs will reduce the amount of excessive force in their departments. Nearly $30 \%$ agree/strongly agree, $33.3 \%$ disagree/strongly disagree, and $37.5 \%$ expressed a neutral position $(\mathrm{M}=3.08 ; \mathrm{SD}=1.02)$.

The last two perceptual domains present command staff perceptions of the impact of BWCs on citizens (Fig. 7) and the influence of the public and media on agencies' adoption of BWCs (Fig. 8). Figure 7 shows that $50 \%$ of respondents believe that BWCs will improve citizen behavior during interactions with the police and $43.5 \%$ believe that BWCs will improve citizens' views of police legitimacy $(\mathrm{M}=2.63$; $\mathrm{SD}=0.92$ and $\mathrm{M}=2.74 ; \mathrm{SD}=1.01$, respectively). At the same time, however, almost half $(45.9 \%)$ of command staff believe that BWCs will make citizens and witnesses more reluctant to talk to police $(\mathrm{M}=2.71$; $\mathrm{SD}=1.20)$.

Finally, when asked about the influence of the media and public on the decision to adopt BWCs, command staff expressed relatively consistent perceptions (Fig. 8). Almost $60 \%$ agree/strongly agree that the media will use data from BWCs to embarrass or persecute police and two-thirds $(66.7 \%)$ agree/strongly agree that the use of BWCs is supported by the public because society does not trust police. Furthermore, six out of ten $(60.9 \%)$ agree/strongly agree that pressure to implement BWCs comes from the media $(\mathrm{M}=2.29, \mathrm{SD}=1.16 ; \mathrm{M}=2.33, \mathrm{SD}=1.20$; and $\mathrm{M}=2.35, \mathrm{SD}=1.64$, respectively). However, when asked if there was pressure to implement BWCs from city/state government, no discernible pattern emerged $(\mathrm{M}=3.13 ; \mathrm{SD}=1.45)$.

A breakdown of perceptions across age, sex, race, education, and years of experience in law enforcement indicates that there were more similarities than differences in opinions about BWCs. A mean of means was calculated for each of the perceptual domains to examine differences in the respondents' overall perceptions. ${ }^{6}$ The results indicate that perceptions on the use of BWCs were mixed on all perceptual domains. Regarding overall perceptions on the impact of BWCs on the safety of police officers

\footnotetext{
${ }^{6}$ The comparison of means tables across perceptual domains by age, sex, race, education, and years of experience in law enforcement are available upon request. It should be noted that no inferential statistics were used in this study due to the small sample size. Therefore, there were no statistically significant results to report.
} 
and citizens, respondents with less than 20 years' experience in law enforcement reported greater disagreement with statements concerning improved safety for police and citizens associated with the use of BWCs compared with those with more than 20 years' experience.

Respondents with less than 20 years' experience in law enforcement were generally in strong disagreement with the notion that BWCs would improve citizens' perceptions of the police, whereas their more experienced counterparts were more optimistic. Regarding the statement, "Body-worn cameras will make police officers safer," the more experienced respondents were generally neutral, whereas those with less than 20 years' experience strongly disagreed that BWCs will make police officers safer. Moreover, those with less than 20 years' experience generally did not believe that "Body-worn cameras would make the public safer."

With regard to racial differences, Non-White respondents reported greater disagreement than White respondents with the statement, "Wearing a body-worn camera would affect the behavior of my officers while on duty." Minority participants were generally more inclined to agree that BWCs would be an invasion of citizens' privacy, while White respondents generally disagreed. When it comes to the public/media impact, White respondents were generally in agreement with the statement, "The use of body-worn cameras is currently supported by the public because society does not trust police officers," whereas Non-White respondents appeared to generally disagree with this statement. There were some additional observations. First, regarding the impact of body-worn cameras on police use of force, participants with lower educational achievement expressed stronger disagreement than their more educated counterparts whose responses were closer to neutral. Second, in response to the statement, "Body-worn cameras will improve citizens' views of police legitimacy," female respondents leaned towards disagreement while males leaned more towards agreement.

Overall, command staff members' attitudes were mixed regarding the impact of BWCs on perceptual domains such as police officer effectiveness, safety and the use of force. The results were also mixed on the majority of individual items in the analysis, however, there are some noteworthy findings. Respondents were generally supportive of the use of BWCs, and there is some support for the assumption that race, educational achievement and the length of experience in law enforcement can explain differential perceptions on the use of BWCs. It is also clear that most respondents agree that BWCs will be supported by the public due to growing distrust, and there is also concern about news media coverage and privacy issues. In the following discussion we provide deeper context for these findings and consider some implications regarding the attitudes of police leaders towards the use of BWCs.

\section{Discussion}

The current study examined the perceptions of law enforcement command staff on BWCs. Few studies have focused on the perceptions of officers and very little work has been devoted to examining leadership perceptions. As asserted by Jennings and Fridell (2015) it is imperative to get "buy-in from these key stakeholders" that will ultimately have a heavy hand in decisions on implementation, resource management, and policies related to BWCs (p. 7). Ultimately, the perceptions of law enforcement leadership could 
either make the possible transition to BWCs less disruptive or situate departments in climates that are less than favorable for something that may be inevitable.

As indicated in our results, the majority of command staff were in favor of the use of BWCs, while about a third were not supportive. Most departments were not currently using BWCs, however multiple departments were either planning on or considering BWCs. Command staff did not strongly support the notion that BWCs would impact officer effectiveness, but did generally believe that BWCs could impact evidentiary issues including evidence collection and guilty pleas. Further, command staff expressed concern over the use of BWCs to "fish" for evidence against officers and were more likely to express concern about citizens' privacy than officers' privacy. While the majority of command staff agreed that BWCs would impact officer use of force, there was also concern that it would affect their ability to use necessary force. Finally, command staff expressed strong concern that the media will use BWCs to persecute the police, that BWCs are supported by the public because they do not trust the police, and that there is strong pressure from the media to implement BWCs.

There were few noteworthy differences across respondents' demographic characteristics. Non-white command staff members appear more likely to agree that BWCs would not affect officer behavior and that they were an invasion of citizens' privacy. Command staff with less experience were more likely to disagree that BWCs will make officers and public safer and also more likely to express that BWCs would not improve citizens' perceptions of police. Women were also more likely to think that BWCs would not improve citizens' perceptions. One difference was found based on education; those with higher education reflected the sentiment that less excessive force would be used with BWCs. Overall, most differences based on demographics were not noticeable, however, we note the limitation of a small sample size which affected our ability to make strong conclusions.

The notion that the majority of command staff were in favor of BWCs is important for several reasons. First, there has been immense pressure by the media, social activists, the government, and other entities for all police departments to adopt BWCs. The commitment by President Obama to invest $\$ 75$ million in BWCs and the creation of a Task Force (Office of the White House Press Secretary, 2015) demonstrates this is not a fleeting topic, likely to disappear in a few months. Having the support of command staff could prove integral to help with departmental transition and allocation of resources. Second, command staff that are in support of the use of BWCs may impact the perceptions of their officers. If their Chief expresses support, this could make officers also more receptive to BWCs, a notion that could be examined in future research. Past research on officer perceptions prior to the implementation of BWCs suggests that officers are generally supportive of BWCs (Jennings et al., 2014; Katz et al., 2014). Further support by command staff could help with officers that are unsure or more negative toward the use of BWCs. Finally, having command support during policy development and the planning of implementation of BWCs could potentially ease concerns of officers. Command staff input on issues of privacy, footage use, data management, and when cameras should be used is important when attempting to balance officer and public concerns.

However, our findings also suggest that law enforcement leadership has several reservations regarding BWCs. The lack of support for the notion that BWCs will positivity impact police effectiveness and the concern that police may not use necessary 
force when wearing a BWC is particularly interesting. It may be that public pressures to implement BWCs (as indicated by our results) are influencing their responses on support for BWCs, but they remain skeptical on the actual outcomes associated with them. In other words, generally, while the command staff did not seem to be opposed to BWCs, and did express that they may positively impact evidence related issues and reduce unwarranted complaints against officers, they remained cautious about the overall impact of BWCs.

\section{Future Directions and Limitations}

As indicated earlier, inferential statistics could not be used due to sample size, however, there are several demographic comparisons that future research can consider. In some instances command staff that were non-white expressed concerns over the likelihood of behavioral change by officers due to BWCs and concerns about privacy. While it is difficult to generalize these results with our small sample, these preliminary findings suggest further research is needed to better understand differences in perceptions among command staff based on demographics. The findings on education also warrant further attention. Departments with less experienced command staff may have more reservations about BWCs as evidenced by their perceptions that BWCs would likely not make the public or officers safer. Exploring these findings further with larger samples could shed light on why these perceptions may exist. Despite the limitations of a small sample size, modest variation among demographics, and the focus of only one large Southern county, our study opens the door to future research on command staff perceptions. Future research is needed on larger samples utilizing departments across the United States to make comparisons. It would be interesting to see if command staff from other geographical areas have different perceptions than Southern departments.

Additionally, research that examines command staff pre and post implementation of BWCs could also provide further insight on how perceptions may change over time. It may be that command staff that were in favor of BWCs may have more negative perceptions of them once they are implemented or that command staff that were not in favor became more accepting. Katz et al. (2014) reported that officers' perceptions of the effect of BWCs on prosecution became more negative after implementation, with fewer officers reporting BWCs were helpful in submitting evidence, working with the Prosecutor's office, and prosecuting domestic violence cases. It would be interesting to see how the perceptions of command staff may change on items like officer effectiveness and safety once BWCs were implemented. Further research is needed to determine if some perceptions related to BWCs may be impacted more than others and how they may be impacted in terms of support or non-support of continued or expanded use.

\section{Conclusion}

Recently, use of force and police behavior has been a prominent topic in the media highlighted by high-profile police shootings and calls for action against excessive use of force. The use of BWCs to address these issues has been endorsed by the media, government, social activists, and policy makers alike. The lack of empirical research on 
the effectiveness and perceptions of BWCs have led to increased interest in this area by researchers including the current study. Our results showed that the majority of law enforcement leadership were in favor of BWCs, however, they were cautious on the potential positive impact, and some differences on perceptions of BWCs based on demographics existed. Continued research on the perceptions of police officers including command staff and the public is needed to more fully understand this issue.

Acknowledgments The authors would like to thank the command staff that participated in this survey.

Open Access This article is distributed under the terms of the Creative Commons Attribution 4.0 International License (http://creativecommons.org/licenses/by/4.0/), which permits unrestricted use, distribution, and reproduction in any medium, provided you give appropriate credit to the original author(s) and the source, provide a link to the Creative Commons license, and indicate if changes were made.

\section{References}

Abdollah, T. (2014, March 15). Officers fear body cameras raise privacy concerns. Retrieved from http://www. policeone.com/police-products/body-cameras/articles/6976369-Officers-fear-body-cameras-raiseprivacy-concerns/

Ariel, B., Farrar, T., \& Sutherland, A. (2015). The effect of police body-worn cameras on use of force and citizens' complaints against the police: A randomized controlled trial. Journal of Quantitative Criminology, 31, 509-535.

Bradner, E. (2015, August 10). John Kasich 'open' to police body cameras. Retrieved from http://www.cnn. com/2015/08/09/politics/john-kasich-police-body-cameras/

Considering police body cameras: Developments in the law (2015). Harvard Law Review, 128, 1-43.

Drover, P., \& Ariel, B. (2015). Leading an experiment in police body-worn video cameras. International Criminal Justice Review, 25, 80-97.

Fieldstadt, E. (2014, November 26). Should every police officer be outfitted with a body camera? NBC News. Retrieved from http:/www.nbcnews.com/storyline/michael-brown-shooting/should-every-police-officerbe-outfitted-body-camera-n256881

Jennings, W. G., \& Fridell, L. (2015, Spring). The relevance of understanding key stakeholder perceptions toward body-worn cameras. Translational Criminology. Retrieved from http://cebcp.org/

Jennings, W. G., Fridell, L. A., \& Lynch, M. D. (2014). Cops and cameras: Officer perceptions of the use of body-worn cameras in law enforcement. Journal of Criminal Justice, 42, 549-556.

Katz, C. M., Choate, D. E., Ready, J. R., \& Nuño, L. (2014). Evaluating the impact of officer worn body cameras in the Phoenix police department. Phoenix, AZ: Center for Violence Prevention \& Community Safety, Arizona State University.

King, R., \& Disis, J. (2015, August 11). Push for IMPD body cams follows police shooting of teen. Retrieved from http://www.indystar.com/story/news/2015/08/11/push-impd-body-cams-follows-police-shootingteen/31482109/

Macari, J. (2015, April). Body-worn cameras: Concerns and considerations. Retrieved from https://www.bja. gov/bwc/pdfs/North-Carolina-District-Attorneys_Best-Practices-Committee_Body-Worn-CamerasConcerns-and-Considerations.pdf

Miller, L., Toliver, J., \& Forum, P. E. R. (2014). Implementing a body-worn camera program: Recommendations and lessons learned. Washington, DC: Office of Community Oriented Policing Services.

Morgan, R. (2015, July 17). OKC police captain says body-worn cameras worth the expense. Retrieved from $\mathrm{http} / /$ www.tulsaworld.com/communities/claremore/news/okc-police-captain-says-body-worn-camerasworth-the-expense/article d11a9faf-a918-5ec4-9760-9aba86a626cc.html

National Conference of State Legislature (NCSL) (2015, May 29). Law Enforcement Overview. Retrieved from http://www.ncsl.org/research/civil-and-criminal-justice/law-enforcement.aspx

NIJ (2012, September). A primer on body-worn cameras for law enforcement. Retrieved from https://www. justnet.org/pdf/00-Body-Worn-Cameras-508 
ODS Consulting (2011). Body worn video projects in paisley and Aberdeen: Self-evaluation. Glasgow, Scotland: ODS Consulting.

Office of the White House Press Secretary. (2015, May 18). FACT SHEET: Creating opportunity for all through stronger, safer communities. Retrieved from https://www.whitehouse.gov/the-press-office/2015/ 05/18/fact-sheet-creating-opportunity-all-through-stronger-safer-communities

Owens, C., Mann, D., \& McKenna, R. (2014). The Essex body worn video trial: The impact of body worn video on criminal justice outcomes of domestic abuse incidents. College of Policing: Coventry, England.

Police and Crime Standards Directorate (2007). Guidance for the police use of body-worn video devices. United Kingdom: U.K. Home Office.

Rankin, H. (2013). End of program evaluation and recommendations: On-officer body camera system. Mesa, AZ: Mesa Police Department.

Rosenbaum, D. P. (2015, Spring). Body-worn cameras: High expectations for the police, community members, and researchers. Translational Criminology Retrieved from http:/cebcp.org/.

Sherman, L. W., Gottfredson, D. C., MacKenzie, D. L., Eck, J. E., Reuter, P., \& Bushway, S. D. (1998). Preventing crime: What works, what doesn't, what's promising. Washington, DC: National Institute of Justice, U.S. Department of Justice.

Stanley, J. (2015, March). Police body-mounted cameras: With right policies in place, a win for all. Retrieved August, 2015, from https:/www.aclu.org/police-body-mounted-cameras-right-policies-place-win-all.

Stephenson, C., \& Luthern, A. (2015, August 30). Milwaukee to equip all beat cops with body cameras. Retrieved from http://www.jsonline.com/news/wisconsin/milwaukee-to-equip-all-beat-cops-with-bodycameras-milwaukee-to-equip-all-beat-cops-with-body-camer-323341071.html.

Victoria Police Department (2010). Proof of concept study: Body worn video \& in vehicle video. Victoria, British Columbia: Victoria Police Department.

White, M. D. (2014). Police officer body-worn cameras: Assessing the evidence. Washington, DC: Office of Community Oriented Policing Services.

Young, J. (2014). Implementation of a randomized controlled trial in Ventura, California: A body-worn video camera experiment. Unpublished master's thesis, University of Cambridge, Cambridge, England.

John Ortiz Smykla is Professor and Director of the School of Criminology and Criminal Justice at Florida Atlantic University. He earned his Ph.D. from the School of Criminal Justice at Michigan State University. His recent research on mixed methodology was published in the Journal of Criminal Justice Education and American Journal of Criminal Justice. He is co-author (with Frank Schmalleger) of Corrections in the 21st Century, $7 e$.

Matthew S. Crow is Professor and Chair of the Department of Criminology and Criminal Justice at the University of West Florida. He earned his Ph.D. in Criminology from Florida State University. His research on sentencing, conservation policing, police use of force, and offender reentry has appeared in journals such as Deviant Behavior, Journal of Criminal Justice, Police Quarterly, and American Journal of Criminal Justice. $\mathrm{He}$ is co-editor of Offender Reentry: Rethinking Criminology and Criminal Justice, published by Jones \& Bartlett.

Vaughn J. Crichlow is an Assistant Professor in the School of Criminology and Criminal Justice at Florida Atlantic University in Boca Raton. He received his Ph.D. in Criminal Justice from Michigan State University and holds a law degree from the University of London. He also obtained graduate and undergraduate degrees from Rowan University and the University of the West Indies respectively. His research focuses on attitudes toward the police in areas known for high levels of violent crime, policing and the use of technology, private security and comparative issues in law and justice.

Jamie A. Snyder is an Assistant Professor in the Department of Criminology and Criminal Justice at the University of West Florida. She received her Ph.D. in Criminal Justice from the University of Cincinnati. She also holds a Masters in Criminal Justice from the University of Cincinnati and a Bachelors of Science in Psychology from Northern Kentucky University. Her research focuses on predicting and preventing victimization among college students, crime prevention, fear of crime and perceptions of risk, and policing. 